\section{INTEGRATION OF \\ NURSE PRACTITIONERS AND \\ PHYSICIAN ASSISTANTS IN \\ EMERGENCY DEPARTMENTS}

To the editor: I read the recent CJEM publication by Ducharme and colleagues $^{1}$ on the impact of nurse practitioners (NPs) and physician assistants (PAs) in Ontario emergency departments (EDs) with great interest. The authors concluded that "the addition of PAs or NPs to the ED team can improve patient flow in medium-sized community hospital EDs. Given the ongoing shortage of physicians, use of alternative health care providers should be considered." Similarly, a 1996 publication by Hooker and
McCaig ${ }^{2}$ in the American Journal of Emergency Medicine concluded, "Recruitment and use of PAs and NPs may be a cost-effective strategy for improved delivery of emergency services." Indeed, the use of alternative care providers seems to be an effective solution for physician shortage not only in EDs but also in other departments. However, there are issues to be considered with a change of this nature. First, there must be a systematic training, evaluation and certification program for such personnel. Second, the responsibility of the physician as team leader must increase. Physician control and oversight of all procedures that such health care workers perform is particularly important.
These issues necessitate expansion of the roles emergency physicians play to include those of administrator, collaborator and facilitator.

\section{Viroj Wiwanitkit, MD}

Wiwanitkit House, Bangkhae, Bangkok, Thailand

\section{References}

1. Ducharme J, Alder RJ, Pelletier C, et al. The impact on patient flow after the integration of nurse practitioners and physician assistants in 6 Ontario emergency departments. CJEM 2009; 11:455-61.

2. Hooker RS, McCaig L. Emergency department uses of physician assistants and nurse practitioners: a national survey. Am 7 Emerg Med 1996;14:245-9.
Letters will be considered for publication if they relate to topics of interest to emergency physicians in urban, rural, community or academic settings. Letters responding to a previously published CJEM article should reach CJEM head office in Vancouver (see masthead for details) within 6 weeks of the article's publication. Letters should be limited to 400 words and 5 references. For reasons of space, letters may be edited for brevity and clarity.
Les lettres seront considérées pour publication si elles sont pertinentes à la médecine d'urgence en milieu urbain, rural, communautaire ou universitaire. Les lettres en réponse à des articles du JCMU publiés antérieurement devraient parvenir au siège social du JCMU à Vancouver (voir titre pour plus de détails) moins de six semaines après la parution de l'article en question. Les lettres ne devraient pas avoir plus de 400 mots et cinq références. Pour des raisons d'espace et par souci de concision et de clarté, certaines lettres pourraient être modifiées. 